\title{
Total Harmonic Distortion Minimization in Induction Motor using Space Vector Modulation Scheme
}

\author{
D.Banupriya , \\ PG Scholar, \\ Department of EEE, SNS College of Technology, \\ Coimbatore
}

\author{
K.Sheela Sobana Rani, PhD. \\ Assistant Professor, \\ Department of EEE, SNS College of Technology, \\ Coimbatore
}

\begin{abstract}
The most popular and best modulation method used among Pulse Width Modulation (PWM) technique is Space Vector Modulation (SVM) method. SVM generates low Total Harmonic Distortion (THD) and it is well suitable for motor control. Harmonics is one of the major power quality issues occurring in most of the application. SVM holds the major advantage that only one switch is turned on at a time. The proposed model shows the effect of eliminating the lower order harmonics in SVM. MATLAB/Simulink is used develop the model.
\end{abstract}

\section{Keywords}

Space Vector Modulation, Inverters, Total Harmonic Distortion

\section{INTRODUCTION}

Inverters hold the major role in the area of power electronics. It was mainly of two types namely Voltage Source Inverters (VSI) and Current Source Inverters (CSI). VSI are mainly classified into two categories mainly based on the gating signals given. Gating pulses are of square pulses and PWM based. The basic inverters were introduced in the early 1960 's[1]. The main drawback of these inverters is that it contains lower order harmonics when they are applied to lower or medium power applications. This usually happens when squared wave gated inverters are used. The lower order harmonics can be effectively reduced by the usage of PWM gated inverters. Since the width of the pulses in PWM is adjusted, instead of using equal width pulses the harmonic content can be superseded.

Variable Speed AC Dives (VSD), Uninterruptible Power Supplies (UPS), Static Frequency Charges (SFC) are the major applications where inverters are used most commonly. Among the above mentioned applications VSD's are holding its dominant role in many applications. VSD's must have the capability of changing both frequency and voltage according to the speed and other control requirements.

SVM has many advantages when compared to other PWM techniques. In SVM technique the whole inverter is treated as a single unit. Here there is finite number of switching state based on its operation. In general it comprises of six active vectors and two null vectors, totally eight switching states. This SVM technique can be expanded from normal three phase inverters to multilevel inverters based on its requirement and application.
Reduction of the harmonic content in the power electronics circuits is one of the major issue faced. The harmonics in the system are reduced by many methods. Selective Harmonic Elimination (SHE) technique is one of the efficient for harmonic reduction. Optimization algorithms can be used for programming the switching pulses [5], [6].

When more than two inverters are connected in parallel the problem of ZSCC arises in the system.[7] The main harmonic contributing for ZSCC is the triplen harmonics. So here works are done towards reducing the triplen harmonics which in turn reduces the ZSCC.

\section{SPACE VECTOR MODULATION}

In SVM technique, the combined effect of three phases is considered as one vector. Firstly three phase s are converted into two phases for simplicity [2]. Here space vectors are expressed as any time varying quantities which always sum to zero and are separated by $120^{\circ}$ are expressed as space vectors.

Here three phase systems are defined as $V 1(t), \quad V 2(t), \quad V 3(t))$ can be represented uniquely by a rotating vector,

$$
V=V_{A}(t)+V_{B}(t) e^{j 2 \Pi / 3}+V_{C}(t) e^{j 2 \Pi / 3}
$$

where,

$$
\begin{aligned}
& V A(t)=V m \sin \omega t \\
& V B(t)=V m \sin (\omega t-2 \square / 3) \\
& V C(t)=V m \sin (\omega t+2 \square / 3)
\end{aligned}
$$

Here three phase frames are converted into two phase frames using any transformation technique. Here Clarks transformation is used for three phase to two phase transformation.

$$
\left|\begin{array}{l}
v_{x} \\
v_{y}
\end{array}\right|=\left|\begin{array}{ccc}
1 & -1 / 2 & -1 / 2 \\
0 & \sqrt{3} / 2 & -\sqrt{3} / 2
\end{array}\right| \begin{aligned}
& v_{a 11} \\
& v_{11} \\
& v_{c 1 L}
\end{aligned} \mid
$$

In a three-phase system, the vectorial representation is achieved by the transformation given in figure1. 
vB

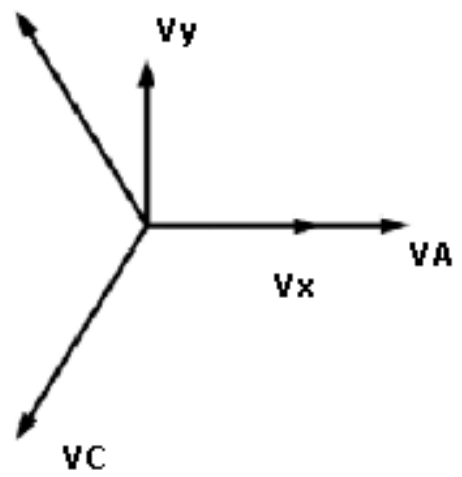

Figure 1. Relation between Stationary frames and $x y$ frames

Vy),

The orthogonal two phase system are given as $(\mathrm{Vx}$,

Where,

$$
\mathrm{V}=\mathrm{V}_{\mathrm{x}}+\mathrm{j} \mathrm{V}_{\mathrm{y}}
$$

The VSI configuration is shown in figure 2. Three phase normal inverters is used here and the inverter is connected at the voltage between $+\mathrm{V}_{\mathrm{DC}} / 2$ and $-\mathrm{V}_{\mathrm{DC}} / 2$.

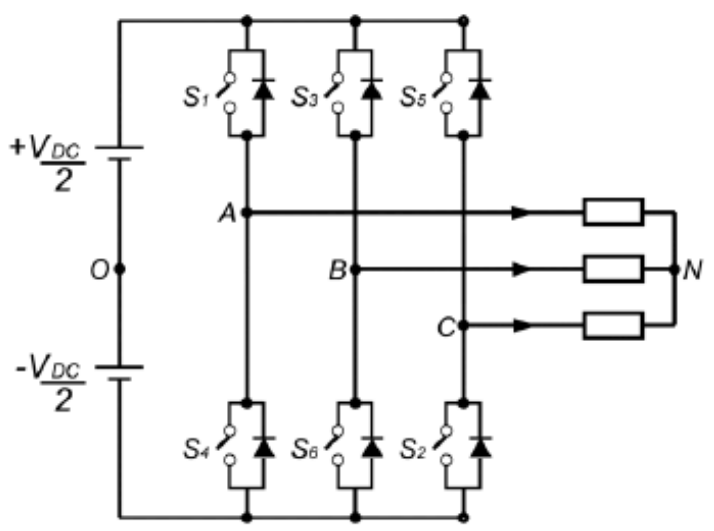

Figure 2. Three phase inverter configuration

As per the operation of SVM, there are only eight possible switching combinations for a three phase inverter and those patterns are briefed as shown in table 1.

\begin{tabular}{|c|c|c|c|c|c|c|c|c|c|}
\hline \multirow{2}{*}{$\begin{array}{l}\text { Voltage in } \\
\text { Vectors }\end{array}$} & \multicolumn{3}{|l|}{$\begin{array}{l}\text { Switcling } \\
\text { Vectors }\end{array}$} & \multicolumn{3}{|l|}{$\begin{array}{l}\text { Line - Neutral } \\
\text { Voltage }\end{array}$} & \multicolumn{3}{l|}{ Line - Line Voltage } \\
\cline { 2 - 11 } & $\mathrm{A}$ & $\mathrm{B}$ & $\mathrm{C}$ & $\mathrm{V}_{\mathrm{ma}}$ & $\mathrm{V}_{\mathrm{ta}}$ & $\mathrm{V}_{\mathrm{cn}}$ & $\mathrm{V}_{\mathrm{ab}}$ & $\mathrm{V}_{\mathrm{bc}}$ & $\mathrm{V}_{0}$ \\
\hline $\mathrm{V}_{0}$ & 0 & 0 & 0 & 0 & 0 & 0 & 0 & 0 & 0 \\
\hline $\mathrm{V}_{1}$ & 1 & 0 & 0 & $2 / 3$ & $-1 / 3$ & $-1 / 3$ & 1 & 0 & -1 \\
\hline $\mathrm{V}_{2}$ & 1 & 1 & 0 & $1 / 3$ & $1 / 3$ & $-2 / 3$ & 0 & 1 & -1 \\
\hline $\mathrm{V}_{3}$ & 0 & 1 & 0 & $-1 / 3$ & $2 / 3$ & $-1 / 3$ & -1 & 1 & 0 \\
\hline $\mathrm{V}_{4}$ & 0 & 1 & 1 & $-2 / 3$ & $1 / 3$ & $1 / 3$ & -1 & 0 & 1 \\
\hline $\mathrm{V}_{5}$ & 0 & 0 & 1 & $-1 / 3$ & $1 / 3$ & $2 / 3$ & 0 & -1 & 1 \\
\hline $\mathrm{V}_{6}$ & 1 & 0 & 1 & $1 / 3$ & $-2 / 3$ & $1 / 3$ & 1 & -1 & 0 \\
\hline $\mathrm{V}_{7}$ & 1 & 1 & 1 & 0 & 0 & 0 & 0 & 0 & 0 \\
\hline
\end{tabular}

Table 1. Switching patterns and voltage of SVM

As shown in Table1, the vector 0 is used to represent the negative phase voltage level and vector 1 represents the positive phase voltage level. The non-zero vector namely $V_{1}$ to $V_{6}$ shape the hexagon axis and the angle between two nonzero vectors is $60^{\circ}$. The null vectors $\mathrm{V}_{0}$ and $\mathrm{V}_{7}$ represent the short circuit on the output, where others are vectors in $x-y$ plane. These eight vectors are called the space vectors.

\section{BLOCK DIAGRAM}

The proposed technique is to reduce the total harmonic distortion and zero sequence circulating current when inverters are connected in parallel. The total system comprises of a SVM pulse generator, inverter circuit and an induction motor load.

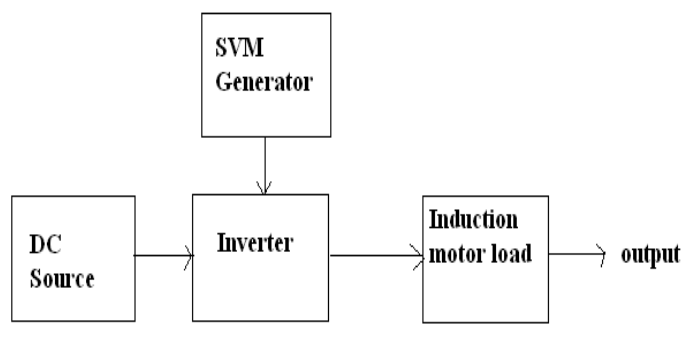

Figure 3. Block diagram of the system

Figure 3 gives the block diagram of a single inverter when connected to a load. So here the harmonic reduction alone is concentrated and the effect of ZSCC is not present. 


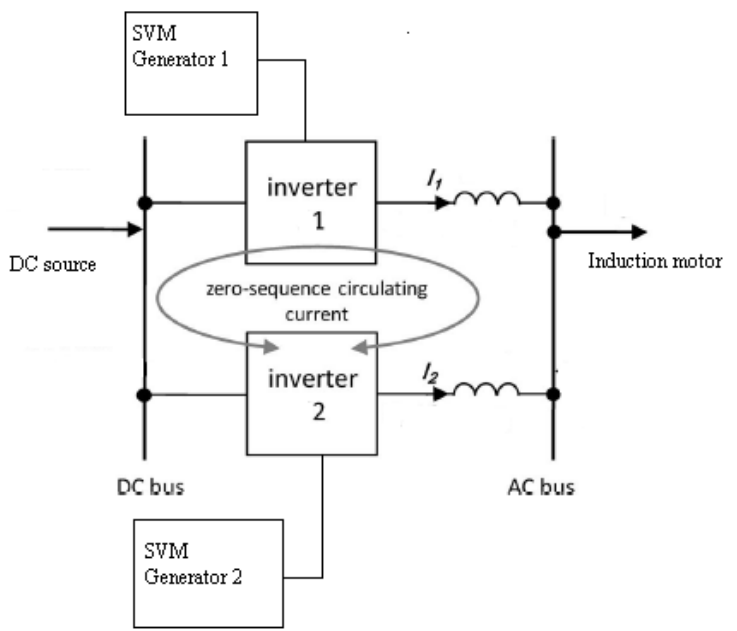

Figure 4. Block diagram when inverters are connected in parallel

Here the block diagram describes the overall operation of the system. The SVM pulses are generated using pulse generator and those pulses are given as input to the inverters. Three phase induction motor load is used here and the harmonics and zero sequence current are studied using the system.

\section{SIMULATION AND RESULTS}

A three phase SVM gated inverter with Synchronous motor load is considered. A complete mathematical model of the SVPWM is developed and simulated using MATLAB/Simulink to investigate the performance of a three phase inverter.

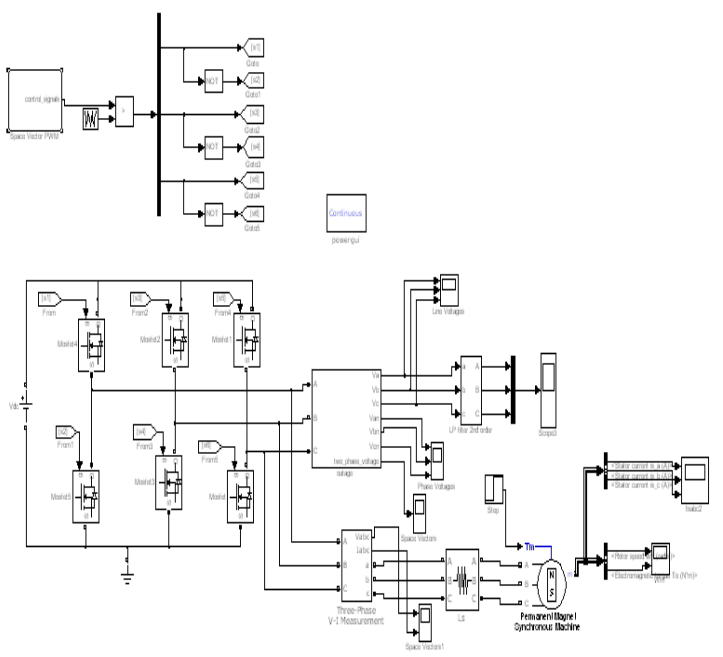

Figure 5. Simulation of three phase inverter with SVM technique

\section{RESULTS}

Figure 5 shows the motor current produced in the system.

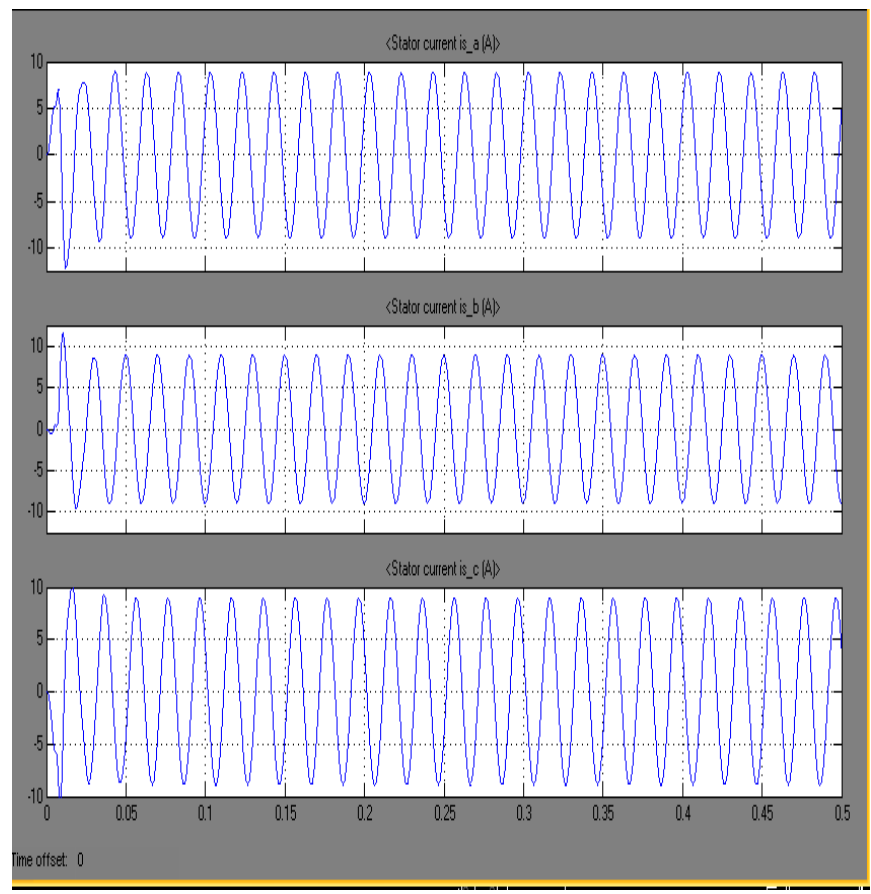

Figure 6. Motor Current results

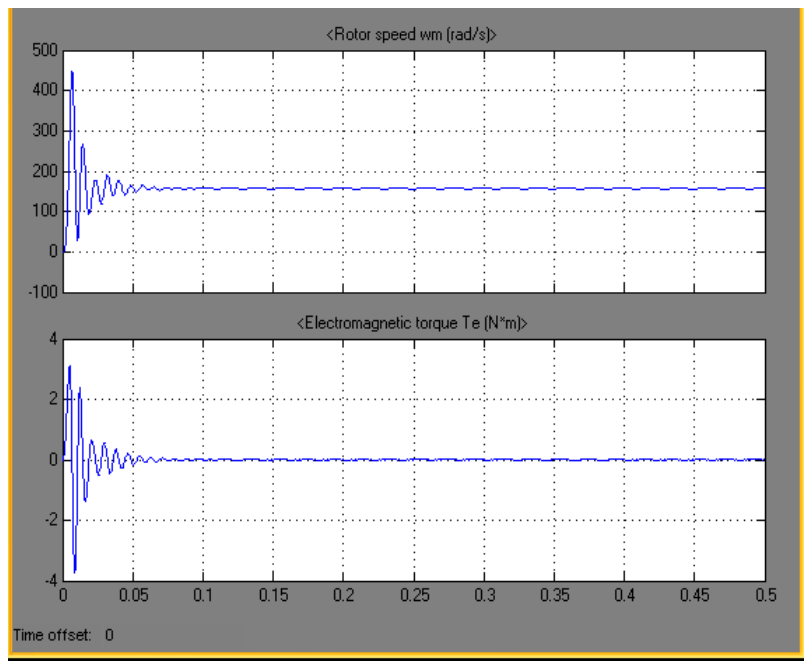

Figure 7. Motor speed and Torque 


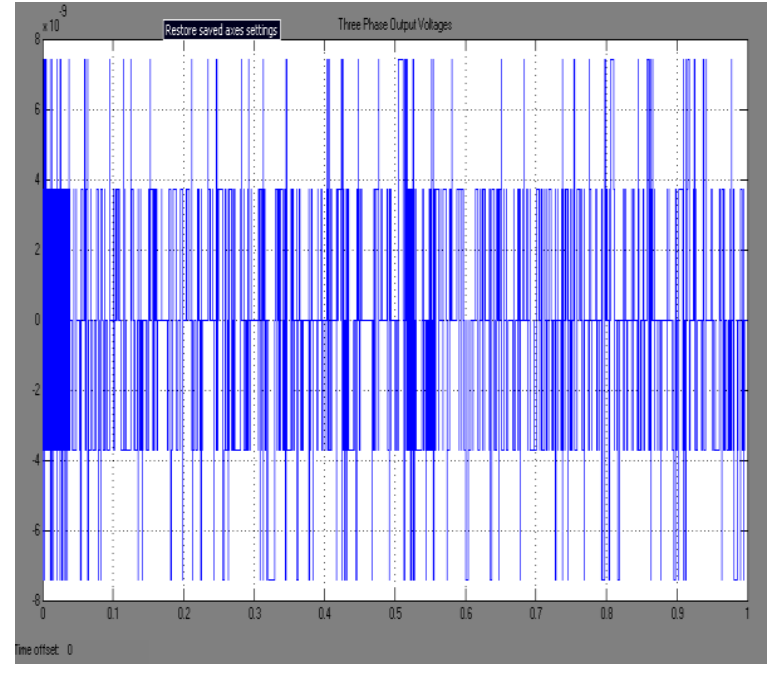

Figure 8. Zero Sequence Circulating Current

The THD values measured after the development of the system is tabulated to analyze the efficiency or result obtained. The THD is mainly concentrated on the stator phase output current. The harmonics present in the three phases are so found form the simulation done. The result obtained proves that the distortion in the system is less.

The tabulation shows the values of the harmonics in the system and also the system appendix

\begin{tabular}{|l|c|c|c|c|}
\hline & $\begin{array}{l}\text { Voltage } \\
\text { in Volts }\end{array}$ & $\begin{array}{l}\text { Frequency } \\
\text { in Hertz }\end{array}$ & $\begin{array}{l}\text { Modulati } \\
\text { on Index }\end{array}$ & $\begin{array}{l}\text { THD of } \\
\text { Stator } \\
\text { Currents }\end{array}$ \\
\hline $\begin{array}{l}\text { Phase } \\
\text { a }\end{array}$ & 400 & 50 & 0.8 & $0.49 \%$ \\
\hline $\begin{array}{l}\text { Phase } \\
\text { b }\end{array}$ & 400 & 50 & 0.8 & $0.48 \%$ \\
\hline $\begin{array}{l}\text { Phase } \\
\mathrm{c}\end{array}$ & 400 & 50 & 0.8 & $0.47 \%$ \\
\hline
\end{tabular}

Table 2. THD analysis of load currents

\section{CONCLUSION}

Here the mathematical model of a SVM based three phase inverter is formulated and simulations are done with MATLAB/Simulink. From the results it can be given that the total harmonic distortion can be reduced appreciably and thereby, the zero sequence circulating current can also be reduced. This model can be applied to various motor applications and also to non-linear loads to get a less distortion results.

\section{ACKNOWLEDGMENT}

We thank to Dr.R.Subramanian, Asst.Prof. R.Karthick and Asst.Prof. R,Rajasekaran of the Electrical and Electronics Department, SNS College of Technology, Coimbatore, for their contribution of this work.

\section{REFERENCES}

[1]. B. K. Bose, "Adjustable speed AC drives - A technology status review," Proceedings of the IEEE- IECON, vol. 70, pp. 116-135,

[2]. Feb. 1982. Nisha G. K., Ushakumari S. and Lakaparampil Z. V "Harmonic Elimination of Space Vector Modulated Three Phase Inverter" proceedings of International MultiConferernce of Enhineers and Computer Scientists 2012 Vol II.

[3]. M. S. A. Dahidah and V.G. Agelidis, "Selective harmonic elimination PWM control for cascaded multilevel voltage source converters: A generalized formula," IEEE Transactions on Power Electronics, vol. 23, no. 4, pp. 1620 - 1630, 2008.

[4]. V. G. Agelidis, A. I. Balouktsis, and M. S. A. Dahidah, "A five level symmetrically defined selective harmonic elimination PWM strategy: Analysis and experimental validation," IEEE Transactions on Power Electronics, vol. 23, no. 1, pp. 19-26, Jan. 2008.

[5]. J. R. Wells, B. M. Nee, P. L. Chapman and. T. Krein,“ Selective harmonic control: a general problem formulation and selected solutions," IEEE Transactions on Power Electronics, vol. 20, pp.1337-1345, Nov. 2005.

[6]. Mehrizi-Sani and S. Filizadeh, "An optimized Space Vector Modulation Sequence for Improved Harmonic Performance," IEEE Transactions on Industrial Electronics, vol. 56, no. 8, pp. 28942903, Aug. 2009.

[7]. Tsung-Po Chen, 'ZZero-Sequence Circulating Current Reduction Method for Parallel HEPWM Inverters Between AC Bus and DC Bus'" in IEEE Transactions On Industrial Electronics, Vol. 59, No. 1, January 2012.

[8]. D. G. Holmes and T. A. Lipo, "Pulse Width Modulation for Power Converters: Principles and Practice," New Jersey: Wiley IEEE Press,2003.

[9]. J. Holtz, P. Lammert and W. Lotzkat, "High speed drive system with ultrasonic MOSFET PWM inverter and single-chip microprocessor control," IEEE Transactions on Industry Applications, vol. 23, pp. 1010-1015, 1987.

[10].H. W. Van der Broeck, H. C. Skudelny and G.V. Stanke," Analysis and realisation of a pulse width modulator based on voltage space vectors", IEEE Transactions on Industry Applications, vol. 24, pp. 142-150, Jan./Feb. 1988 